\title{
DISSEMINA'TED MILIARY TUBERCULOSIS OF LUNGS AND SKIN *
}

\author{
W. P. NORTHRUP, M.D. \\ Professor of Pediatrics, New York University and Bellevue Medical College. \\ NEW YORI
}

The diagnosis of miliary tuberculosis in the very young is difficult. In the lungs, for instance, without consolidation and without cavity, miliary tuberculosis may be strongly suspected, but not easily proved.

I submit herewith two helps to the diagnosis - one, of the lungs the $\mathrm{x}$-ray; the other of the skin - the eruption. The first case selected for illustration shows both diagnostic signs and will be submitted complete. The best recent $x$-ray apparatus has made it possible to produce the accompanying pictures, which speak for themselves. In six cases of infants and young children suspected of disseminated miliary tuberculosis of the lungs, the $x$-ray has cooperated with other tests to decide the diagnosis. For illustration of what can be done, the kest $\mathrm{x}$-ray plate has been selected, the best print made from it and the best result obtainable here presented (Fig. 1).

The second help to the diagnosis of general miliary tuberculosis in the young is general miliary tuberculosis of the skin. The localized lesions of the skin so often described, are not here meant. (See Figs. 2, 3 and 4.)

CASE 1. General miliary tuberculosis; involvement of skin.

Dorothy K., 21/2 years old, was admitted to the Presbyterian Hospital with the diagnosis of pneumonia. The case presents the following points of interest: 1. The patient had the appearance and the chart of $\boldsymbol{a}$ child sick with pneumonia but with the physical signs of bronchitis. 2. The exact diagnosis was made by x-ray (lungs), (Fig. 5). 3. There was the unusual skin eruption of disseminated miliary tuberculosis. (Figs. 2, 3, 4.) 4. A necropsy completed the record and confirmed all previous findings.

1. Physical signs: As to the "look and chart" of pneumonia in this child, the temperature ( $\mathrm{T}$ ) was high and continuous, 102 to $105 \mathrm{~F}$; the pulse (P) was 130 to 160 per minute; the respiration (R) was 42 to 72 ; out of normal proportion to the pulse; the R-P ratio was "disturbed." "When the R-P ratio departs from the normal of $1 / 4$ and approximates $1 / 3$, look for pneumonia" (O'Dwyer). It is to children that I would apply this; it is not so valuable in adults.

It would be exceptional for a pneumonia patient to remain in hospital a week developing a severe febrile reaction, without revealing some signs of consolidation. Presumably all clinical men will think there is here shown good reason for the diagnosis of tuberculosis. That is granted. For exact diagnosis by means of new and high grade mechanical appliances, however, we may still contend.

* Read before the Association of American Physicians, Washington, D. C., May 7, 1913. 


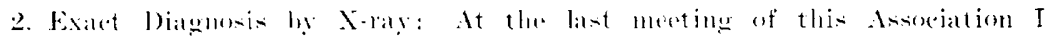

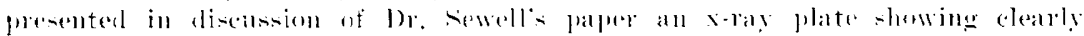

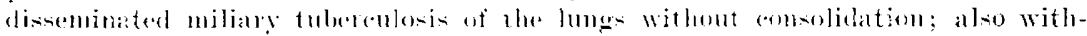

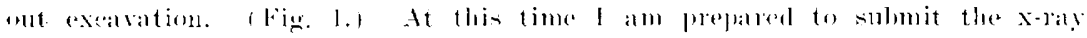

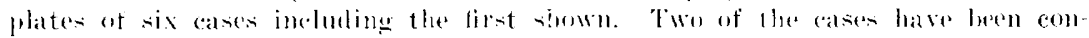

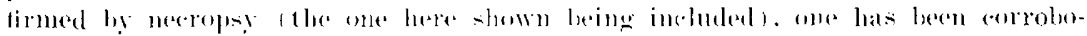

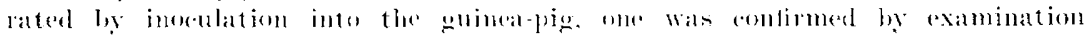

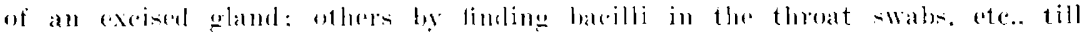
we can be rationally cortain that our x-lay dindings are reliable and trustworthy.

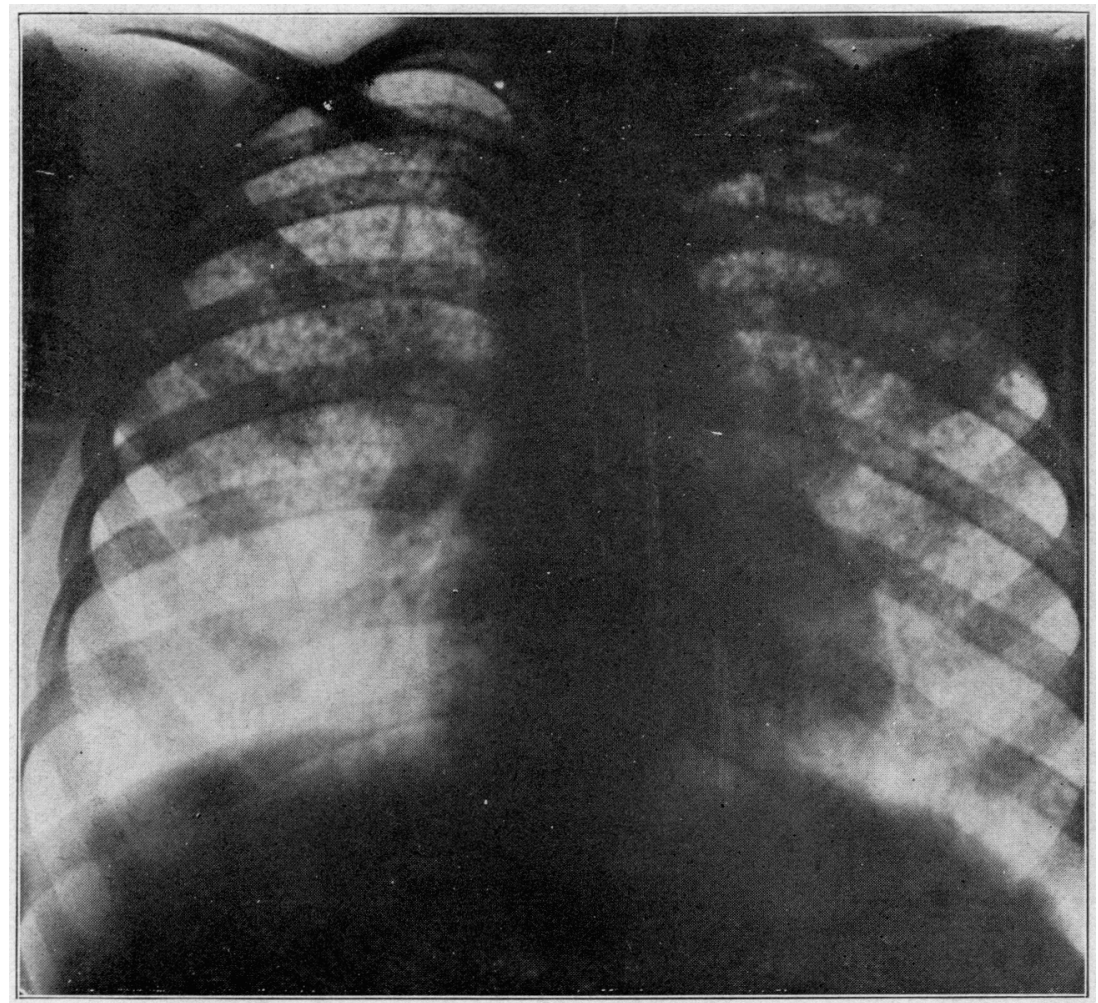

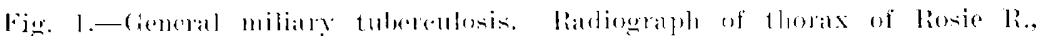

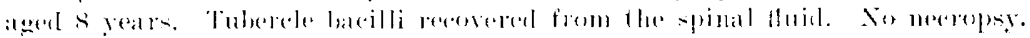

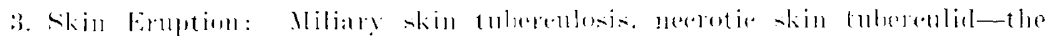

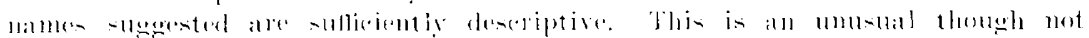

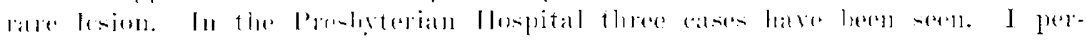

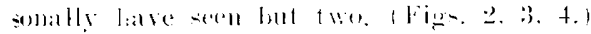

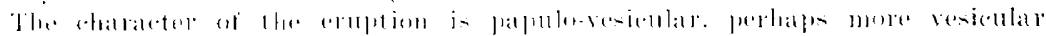

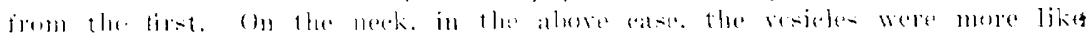

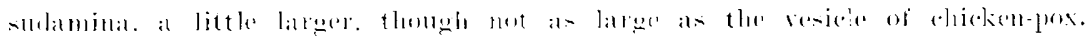

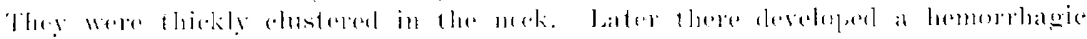

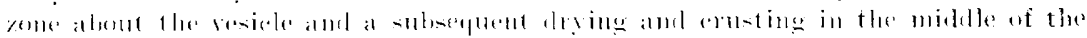

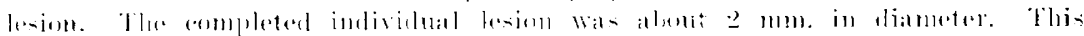

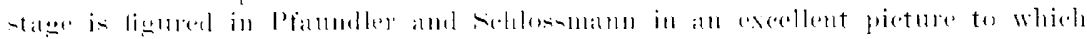

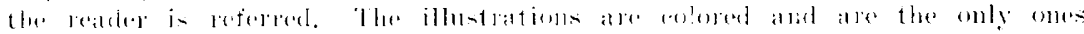


known to us. The accompanying photographs of the prosent case, in black and white, show to good advantage. (Figs. 2, 3, 4.) The rash was on all skin surfaces, including soles, palms and scalp, with more about the mouth, anus and buttocks. The superficial lymph-nodes were enlarged everywher the liver was enlarged. Naturally the case attracted a good deal of attention. Col. leagues who wore called in to see the case expressed their views. one suggesting syphilis, another chicken-pox. The rash is said to have been evident three days before entrance, appearing first about the mouth, neck and chest.

4. Necropsy: The brain was not examined; tubercles were found in the lungs, splcen, kidneys, liver. etc. Tubercle bacilli were found in clumps in the blood of the luart in any casual smear. Smears taken from the skin vesicles showed such quantities that the spread-out corium was faintly pink from the stained bacilli. The case was acute, which may have determined the character of lesions.

It is interesting to note that the structure of the tubercles was not the usual structure; in fact, strictly speaking, they were not tulercles at all. More

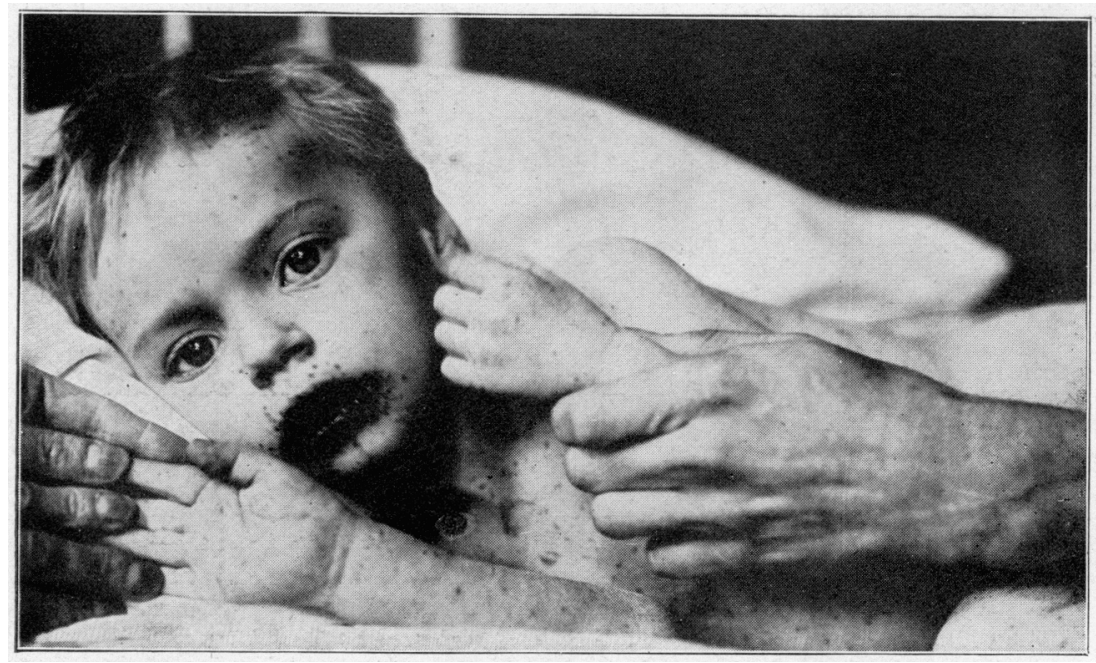

Fig. 2.-Miliary tuberculosis of the skin. Papulo-vesicles; hemorrhagie crusts (umbilicated). Properly, necrotic tuberculid.

properly speaking, the Jesion was necrotic tuberculosis ("tuberculid"); there was no tissue reaction at all, merely melting down into necrosis where tuberele bacilli stopped and began to grow. There was no connective tissue reaction, no giant cells, no surrounding zone of epithelioid and mononuclear wandering cells. "There were just necrotic areas filled with tubercle bacilli. In none of the zones were found evidences of protective reaction" (I)r. Jamb). Simply larger and smaller areas of necrosis, lymph-nodes and tonsils containing the same.

Six cases are shown in the $x$-ray plates. All of the patients came into the hospital with the evidence in faror of acute pneumonia, the chart bearing out the general suggestion and appearance of the disease. 'The $x$-ray was really the first means of positive diagnosis, being subsequently confirmed by finding tubercle bacilli. 
Thuberculous eruption on the skin, necrotic tuberculid, discominated miliary tuberenlosis of the skin, sugegent in their names the characteristies of the lexions under consideration.

Cask 2.-Ceneral ntiliary tubereulosis involving the skin in a clild aged 18 montlis. Jied. No autopsy.

Late $\mathrm{N}$. entered the l'reshyterian ITospital with the diagnosis of pneumonia. The onset was abrupt three day before, with drowsiness, ferer, cough and a peculiar, unrecognized rash.

Fxamination showed a temprerature of 101 to $103 \mathrm{~F}$.. rising to $105.5 \mathrm{~F}$. at or just lefore death, cough. coarese rales over both lungs, harsh breathing and voice orey irrenular areas. jest esiness. flaring nostrils-satisfactory evidences

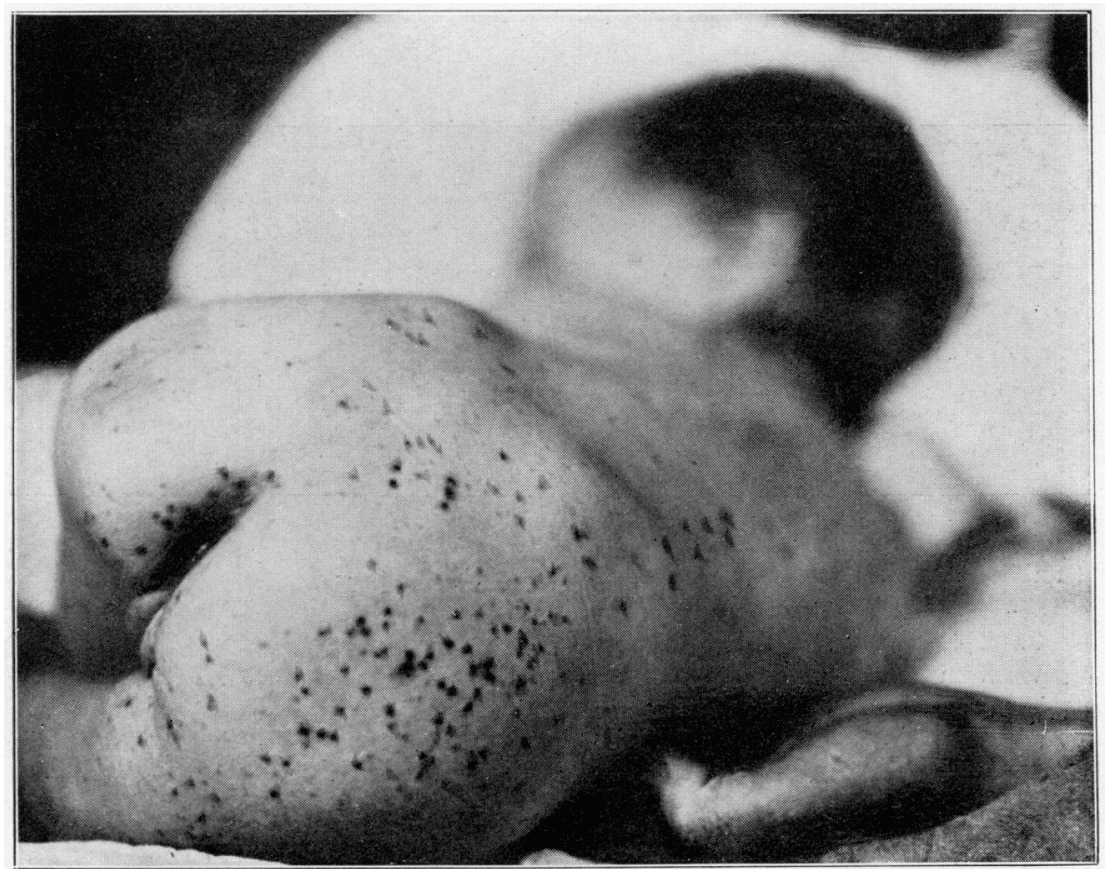

Fig. 3.-Tuberculosis of skin; papulo-vesicular; crusts (umbilicated); hemorrhagic. Properly, necrotic tuberculid.

of pneumonia. As the Rocntgen-ray was not in common use at that 1ine, no radiographs can be shown. There was no autopsy. No bacilli were found.

Skin Eruption: In orler of time, this case was the first case that had come uncier the observation of the staff and was not recognized until an excel. lent colored illustration in Pfambler and Schlossmann was noticerl. It is important to have this case in mind in deciding on skin eruptions, for those who see one case and recognize its character will never make a mistake. Witness the fact that the two cases accompanying this were recognized instantly by those who saw the first. and by no others present.

The eruption was discrete, papulo-vesicular, later drying, "topped with a scalb," about $2 \mathrm{~mm}$. in diamoter. and. as the recorder says, "suggostive of chickenpox, except that the papules are small." 
An expert from the Board of Health pronounced it a late stage of chickenpox, thus explatining why they were so small.

The lesion is called by P'aundler and Schlosimann "necrotic tuberculid."

CASE 3.-Pulmonary tuberculosis and skin tulereulids.

John II.. 15 months old. This patient also came to hospital with the diag. nosis of acute pneumonia. The patient died; no necropsy and no radiographs made, but the tissues of the skin lesion were inoeulated into guinea-pigs and proved to be tuberculosis.

The patient was in hompital five diays. in a dying condition all the time. The lungs showed râles everywhere. bronchial voice and breathingr. harsh in nature.

The main interest centers about the skin lexion. small pin-head-sized and a little larger papules with small necrotic centers. There were a few on the arms and legs. a few on the balek and front of the trunk, also one or two on the thighs. There were a few small ecchymotic spots on the thighs. The diagnosis was pulmonary tuberculosis, and on the skin, tuberculids. When engrafted in the guinea-pig. typical tuberculosis in the internal organs was developed.

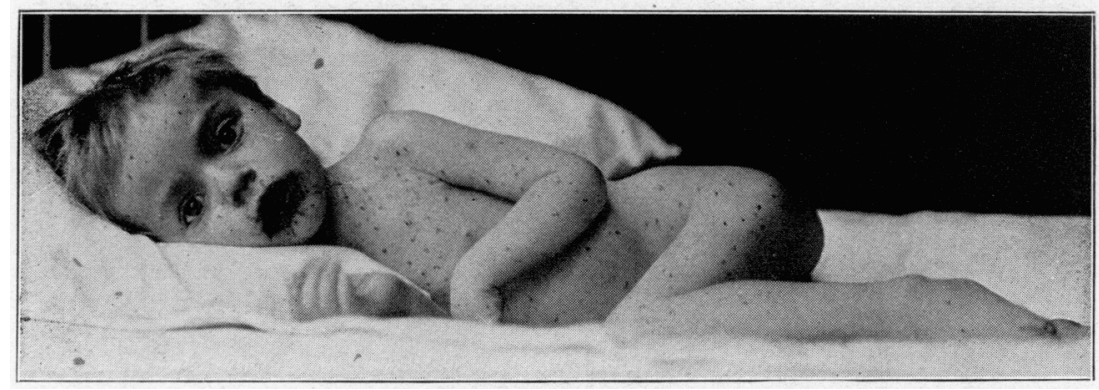

Fig. 4.-Miliary tulerculosis of skin: papulo-vesicular; hemoulatgic; erusts (umbilicated). Properly, necrotic tuberculid.

CASF: 4.- General miliary tulyereulosis of lungs; x-ray; autopsy.

William F. (colored), aged 10 months, entered the hospital with the diagno-is of pnemmonia. There ware fever, apathy ("dopey"), R-P ration disturbed. $1-3$; respiration, 36 to $50 \mathrm{per}$ minute; pulse, 110 to $150 \mathrm{per}$ minute, irregular; temperature, 100.5 to $102.5 \mathrm{~F}$ : a discharging ear; romiting-manifestly a very sick child; no consolidation of the lungs, no tubercle bacilli found. no history of râles in the chest. The liagnosis was suspected from the history and chart but not confirmed till the x-ray showed it elearly and unmistakably. This was one of the best proofs of the value of the x-ray. As to rales, they were probably to be found at favorable moments. after a long interval of uninterrupted quiet. The hospital intern states that the lungs were clear in front and belind. Spinal fluil was perfectly clear. Noguchi-lVasiormann test of blood and spinal fluid was negative.

This case, also entered an one of pnemonia. Was then believed to be tuberculosis from the history and chart, and the diagnosis was confirmed by the $x$-ray and at lant by autopsy. The radiograph was one of the hest of the series.

(Asl: 5.--Diagnosis on admission, acute iubereulous boncho-pneumonia. General tuberculosis. Diod. No necropst.

Vieto S., aged 3 years. This case is one in which there was good gromnd for believing that there was tubereulosis, and the $x$-ray was convineing; there was also confirmation later from the tissue of a superficial ghand.

('ASE 6.-Diagnosis on admission, general bonehitis, probalyy tubereulous. X-ray convincing. No corroboration. No necropsy. 


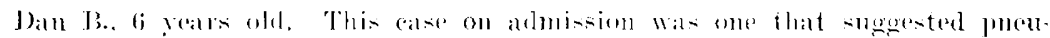

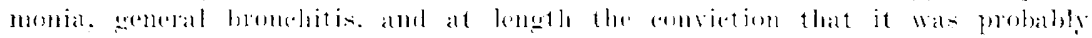

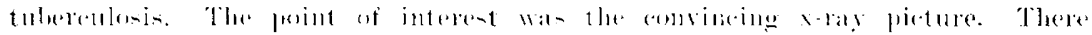

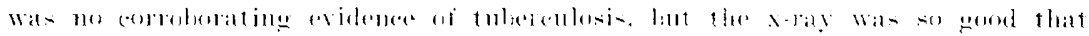

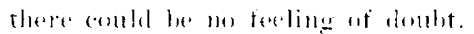

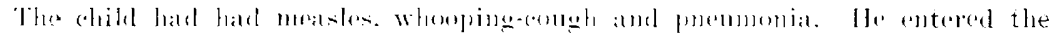

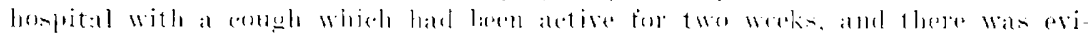

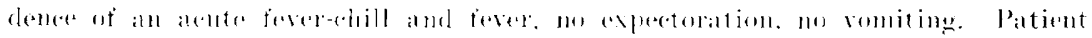

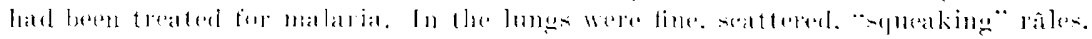

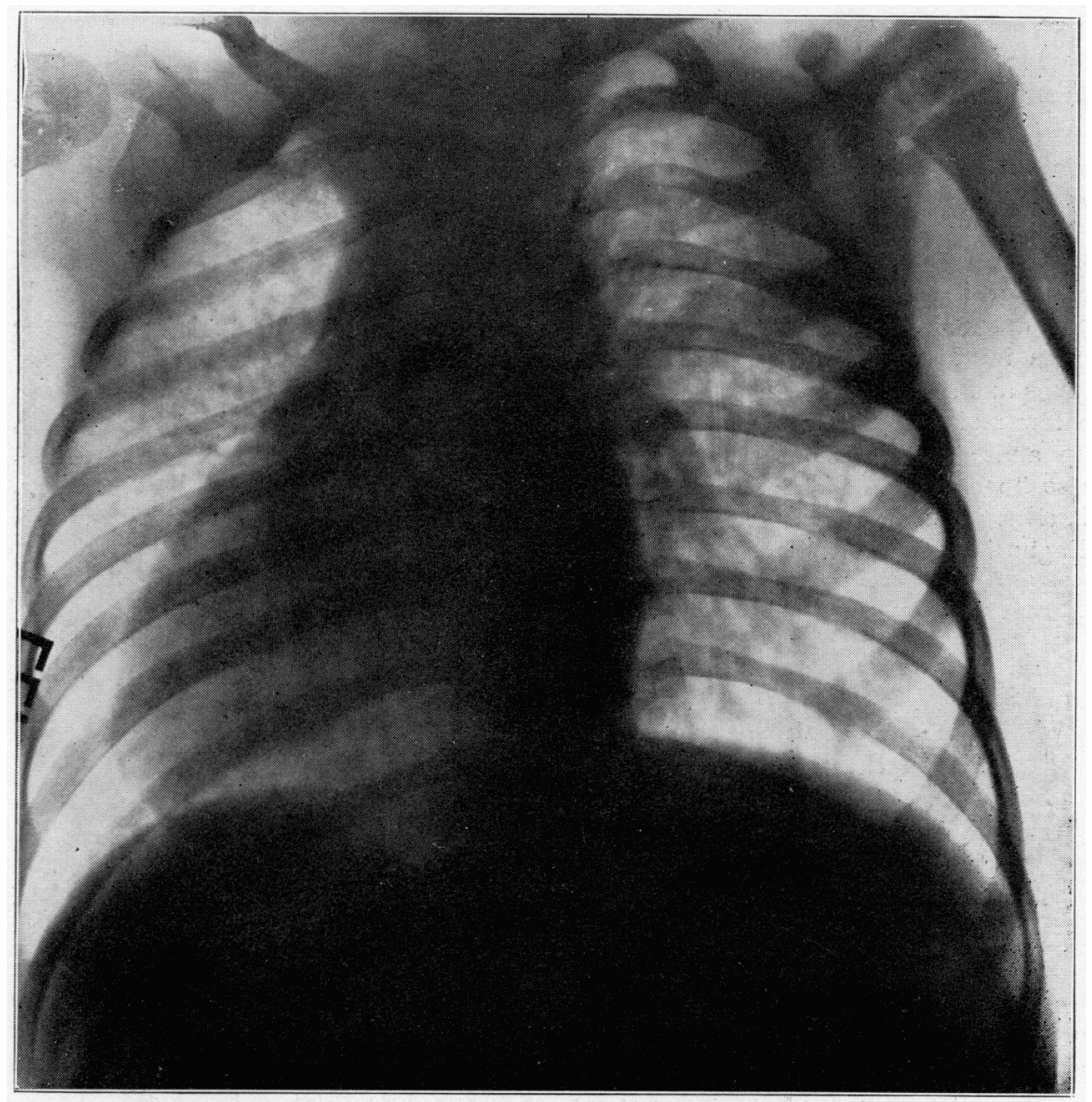

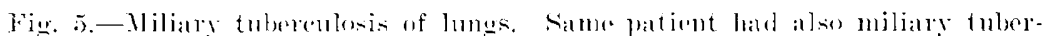

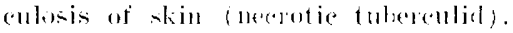

There were thomght to be aretain localities in which the lowathing sounds indicated a molerate andemsition of the lungs. but the x-ray dis not corroborate

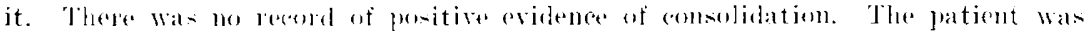

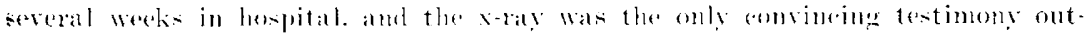
side of that dinicall.

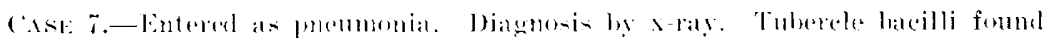
in spinal lluid. No neceropers.

Rosie li. This sigear-old child was in the hospital twenty-five days. running

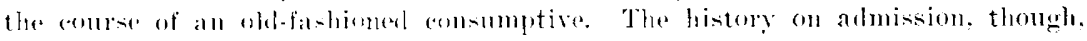


suggested pneumonia-cough, expectoration, blood-stained sticky expectoration, stabbing pains in the chest, night-sweats and loss of weight.

The previous history was that of measles at 2 years, bronchitis at 7 . The interest in the case centers in the $x$-ray testimony. It was a convincing picture and was corroborated by finding tubercle bacilli in the spinal fluid. (Fig. 1.)

CASE 8.-Diagnosis on discharge was general miliary tuberculosis of the lungs. $\mathrm{X}$-ray. Improved.

John S., aged 9. The interest in this case rests on these points: A sug. gestive previous history; a positive x-ray picture; "tubercles on the lungs"; good general condition; discharged having no fever and apparently thriving fairly. Sent to the country for still further improvement.

Previous History.-No significant family history or surroundings. Previous illnesses, whooping-cough, measles, and indefinite history of tumors which seem to have been tuberculosis of the lymph-nodes just over sternum and neck. This patient was observed in good hospitals just before coming to the present one, and nothing special was discovered in the lungs. In one particularly good hospital, where the facilities for $x$-ray would probably be excellent, nothing was sought by $x$-ray; at least there was nothing said about it.

Examination.—"Bright boy; does not look ill; ears and cheeks bluish-red; not dyspneic; slightly cyanotic; mentally alert; no noteworthy scars; tongue clean in the middle line; lips very red; cervical and inguinal glands enlarged; Iungs and abdomen negative; extremities and hands bluish; veins of neck enlarged; a few moist râles, most of which clear up on deep breathing; while in hospital, up and about, comfortable, always cyanosed, notably about the ears and lips, also finger-nails. Fluoroscopic examination confirms x-ray plates described above. Patient went to Loomis Sanatorium. Father reports glands are smaller. Clinical diagnosis, cervical tuberculous adenitis.

\section{DISCUSSION}

There is still an added interest to this case. The human interest in a case that by all laws and experience is doomed, yet has gone out of the hospital with lungs thickly studded with miliary tubercles. To be sure, without the recent new appliances above alluded to, the diagnostician might have thought he had made a mistake; the case then would have passed as undetermined and the memory need not concern itself trying to learn anything from it. Whether the further history of this case is ever written cannot now be said. This may be the final outcome - by the use of the $\mathrm{x}$-ray many such histories may accumulate and the profession learn that they have for years been overlooking cases of disseminated miliary tuberculosis of the lung. What the Wassermann reaction is to syphilis, the $\mathrm{x}$-ray promises to be to the diagnosis of lung tuberculosis in children.

These three cases of skin tuberculosis present the characteristic features thus far met in our experience and most of those not recorded by Tileston in his larger experience.

The most profitable impression to carry away from this reading is that the cases present to the experienced observer the mental picture of pneumonia, but the physical signs of bronchitis. At this point the physician may be unable to procure any reliable testimony for exact diagnosis; 
and until a good x-ray picture has been obtained he may but conjecture, and he may never know whether or not he has made the correct diagnosis. Next to an autopsy the $x$-ray gives the most intimate knowledge of the lesion of the child's lung.

Skin eruptions in the feeble and non-resistant are not rare, but are mostly overlooked. The lesion is mainly necrotic, resulting in vesicles. There may be a stage of papulo-vesicle preceding this. The cases here cited are distinctly acute. Our experience leads us to prefer the term given to the lesion by the authors, Pfaundler and Schlossmann, "necrotic tuberculid."

"The fatal result in infants is probably only another manifestation of the more pernicious course of tubereulosis in general in the first years of life."

Briefly stated, the modern $x$-ray apparatus, next to an autopsy, furnishes the most valuable insight to the lung lesion of infants and young children.

Eruption of miliary tubercles furnishes a pathognomonic sign for diagnosis and a valuable, almost conclusive, point for prognosis; that is, the lesion is nearly always associated with a fatal form of tuberculosis in the young child.

'The histology varies with the acuteness of the invasion. The above cases were of the acute type and the vesicles (necroses) were the first revealed lesion. It may be that slower developing lesions would disclose the different types described, viz., "papulo-squamous" and "papulonecrotic" tuberculids, described by Darier and Boeck in 1896.

Bacilli are found frequently in the blood and the eruption and the lesion is probably always embilic.

Among the characteristies of the individual lesions may be mentioned the size, that of a rose spot in typhoid fever, topped by a tiny vesicle, surrounded sooner or later with a congested or hemorrhagic zone, with the formation of a crust, which, when removed, leaves a little pit.

The skin lesion is to be differentiated from that of chicken-pox, moluscum contagiosum and from syphilis.

Experience with this eruption is like that with scurvy in infants once seen the lesion cannot be again overlooked.

57 East Seventy-Ninth Street.

1. Tileston: Arch. Int. Med., July, 1909, iv, 21. 